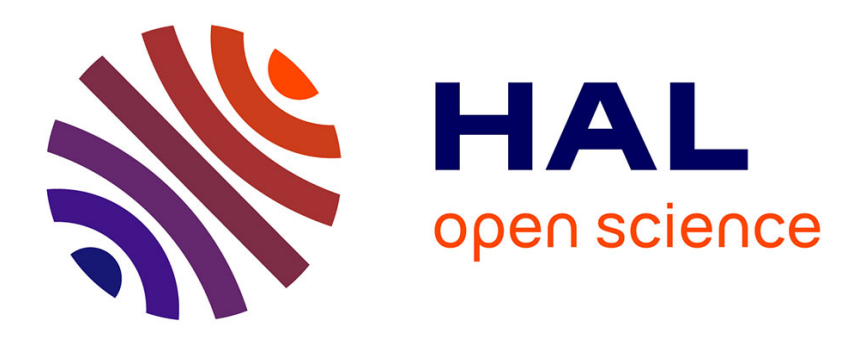

\title{
Stabilization of Austenite Associated with Prior Formation of Martensite
}

\author{
Z. Xie, Yehan Liu, H. Hänninen
}

\section{To cite this version:}

Z. Xie, Yehan Liu, H. Hänninen. Stabilization of Austenite Associated with Prior Formation of Martensite. Journal de Physique IV Proceedings, 1995, 05 (C8), pp.C8-333-C8-338. 10.1051/jp4:1995848 . jpa-00254097

\section{HAL Id: jpa-00254097 https://hal.science/jpa-00254097}

Submitted on 1 Jan 1995

HAL is a multi-disciplinary open access archive for the deposit and dissemination of scientific research documents, whether they are published or not. The documents may come from teaching and research institutions in France or abroad, or from public or private research centers.
L'archive ouverte pluridisciplinaire HAL, est destinée au dépôt et à la diffusion de documents scientifiques de niveau recherche, publiés ou non, émanant des établissements d'enseignement et de recherche français ou étrangers, des laboratoires publics ou privés. 


\title{
Stabilization of Austenite Associated with Prior Formation of Martensite
}

\author{
Z.L. Xie, Y. Liu* and H. Hänninen \\ Lab. of Engineering Materials, Helsinki University of Technology, Puumiehenkuja 3A, 02150 Espoo, \\ Finland \\ * Dept. MTM, Katholieke Universiteit Leuven, de Croylaan 2, 3001 Heverlee, Belgium
}

\begin{abstract}
The stabilization of retained austenite was studied via a two-step cooling procedure. Alloys with $M_{\mathrm{s}}$ temperatures below $0{ }^{\circ} \mathrm{C}$ were used. It was found that the martensitic transformation starting temperature, $M_{\mathrm{s}}$, was lowered to $M_{\mathrm{s}}^{\prime}$ during the second step of cooling. With increasing the amount of previously formed martensite, the difference in the transformation starting temperatures, $\Delta M_{\mathrm{s}}\left(=M_{\mathrm{s}}-M_{\mathrm{s}}\right)$, increases. This stabilization effect can also be observed in an alloy having very low carbon content, and the magnetic properties of alloys do not have drastic effect on the nature of this stabilization phenomenon. The mechanism of the stabilization of retained austenite is proposed to be mainly due to the inhibition effect produced by the previously formed martensite. The aging processes are considered to be a necessary condition for the above mechanism to operate.
\end{abstract}

\section{INTRODUCTION}

It is known that, during an athermal martensitic transformation, if cooling is interrupted at a temperature of $T_{\mathrm{a}}\left(M_{\mathrm{f}}<T_{\mathrm{a}}<M_{\mathrm{s}}\right)$ within the temperature range of martensitic transformation, and aging occurs at $T_{\mathrm{a}}$ or a higher temperature, the transformation stops, and it can recommence only upon additional cooling below the arrest temperature [1-7]. This stabilization of retained austenite has long been attributed to the immobilization of the interfaces between the martensite nucleus and the austenite matrix due to segregation of interstitial solute atoms to the dislocation arrays surrounding the martensite nucleus [2-4]. However, it has to be noted that most of the earlier studies [1-4] have been performed on alloys having $M_{\mathrm{s}}$ temperatures above room temperature, and with both the arrest and aging temperatures higher than $0{ }^{\circ} \mathrm{C}$, where the diffusion of carbon atoms is significant. Studies performed at sub-zero temperatures $[5,6]$ have shown that the stabilization of retained austenite can also develop rapidly in $\mathrm{Fe}-\mathrm{Ni}-\mathrm{C}$ alloys at aging temperatures as low as $-90^{\circ} \mathrm{C}$. These results indicate clearly that the mechanism of the stabilization of retained austenite proposed by earlier researchers [2-4] is not complete since it can not be used to explain the stabilization phenomenon at low temperatures. In fact, it has been noticed in several studies that, for a given aging treatment, the greater the amount of previously formed martensite is, the larger will be the magnitude of stabilization of retained austenite $[6,7]$.

In the present study, the stabilization effect of retained austenite has been studied using Fe-Ni-C alloys with $M_{\mathrm{s}}$ temperatures below $0{ }^{\circ} \mathrm{C}$. The effects of both aging and the previously formed martensite on the stabilization of retained austenite are clarified. A thermodynamical analysis of the effects of the previously formed martensite on the stabilization of retained austenite is also performed. Part of the results have been published in Ref. [8]. In this report, some new data obtained from alloys with high Ni content are added.

\section{EXPERIMENTAL}

Two groups of Fe-Ni-C alloys with different magnetic properties, i.e., paramagnetic matrix phase with low Ni-content and ferromagnetic matrix phase with high Ni-content $[8,9]$, are used in the present study. The alloys, their heat treatment conditions, $M_{\mathrm{s}}$ temperatures and the related martensite morphology are listed in Table 1. The two-step cooling experimental procedure is as follows: the samples were first cooled to a temperature $T_{\mathrm{a}}$ below $M_{\mathrm{s}}$ and then heated to room temperature (RT), after being held at RT for a while, the samples were recooled to low temperatures $(23$ or $82 \mathrm{~K}$ ) and then again heated to RT. The preparation of 
the samples and the test procedure are described in details elsewhere $[8,10]$. The magnetic susceptibilities of the specimens were measured during the whole experimental procedure.

Table 1. Alloys, heat treatment conditions, $M_{\mathrm{s}}$ temperatures and martensite morphology

\begin{tabular}{llcc}
\hline Alloys (wt\%) & $\begin{array}{c}\text { Heat treatment } \\
\text { condition }\end{array}$ & $M_{s}(\mathrm{~K})$ & $\begin{array}{c}\text { Martensite } \\
\text { morphology }\end{array}$ \\
\hline $\mathrm{Fe}-9 \mathrm{Ni}-1.4 \mathrm{C}$ & $1150^{\circ} \mathrm{C} / 1 \mathrm{~h}+\mathrm{WQ}^{*}$ & 248 & Lenticular \\
$\mathrm{Fe}-20 \mathrm{Ni}-0.73 \mathrm{C}$ & $1150^{\circ} \mathrm{C} / 3 \mathrm{~h}+\mathrm{WQ}$ & 226 & Lenticular \\
$\mathrm{Fe}-28 \mathrm{Ni}-0.2 \mathrm{C}$ & $1150^{\circ} \mathrm{C} / 1 \mathrm{~h}+\mathrm{WQ}$ & 237 & Lenticular \\
$\mathrm{Fe}-30 \mathrm{Ni}-0.3 \mathrm{C}$ & $1230^{\circ} \mathrm{C} / 1 \mathrm{~h}+\mathrm{WQ}$ & 236 & Lenticular \\
$\mathrm{Fe}-33.5 \mathrm{Ni}-0.009 \mathrm{C}$ & $1150^{\circ} \mathrm{C} / 1 \mathrm{~h}+\mathrm{WQ}$ & 151 & Lenticular
\end{tabular}

*WQ = water quenched; $1150^{\circ} \mathrm{C} / 1 \mathrm{~h}+\mathrm{WQ}=$ samples were annealed at $1150^{\circ} \mathrm{C}$ for $1 \mathrm{~h}$, and then quenched into salt water.
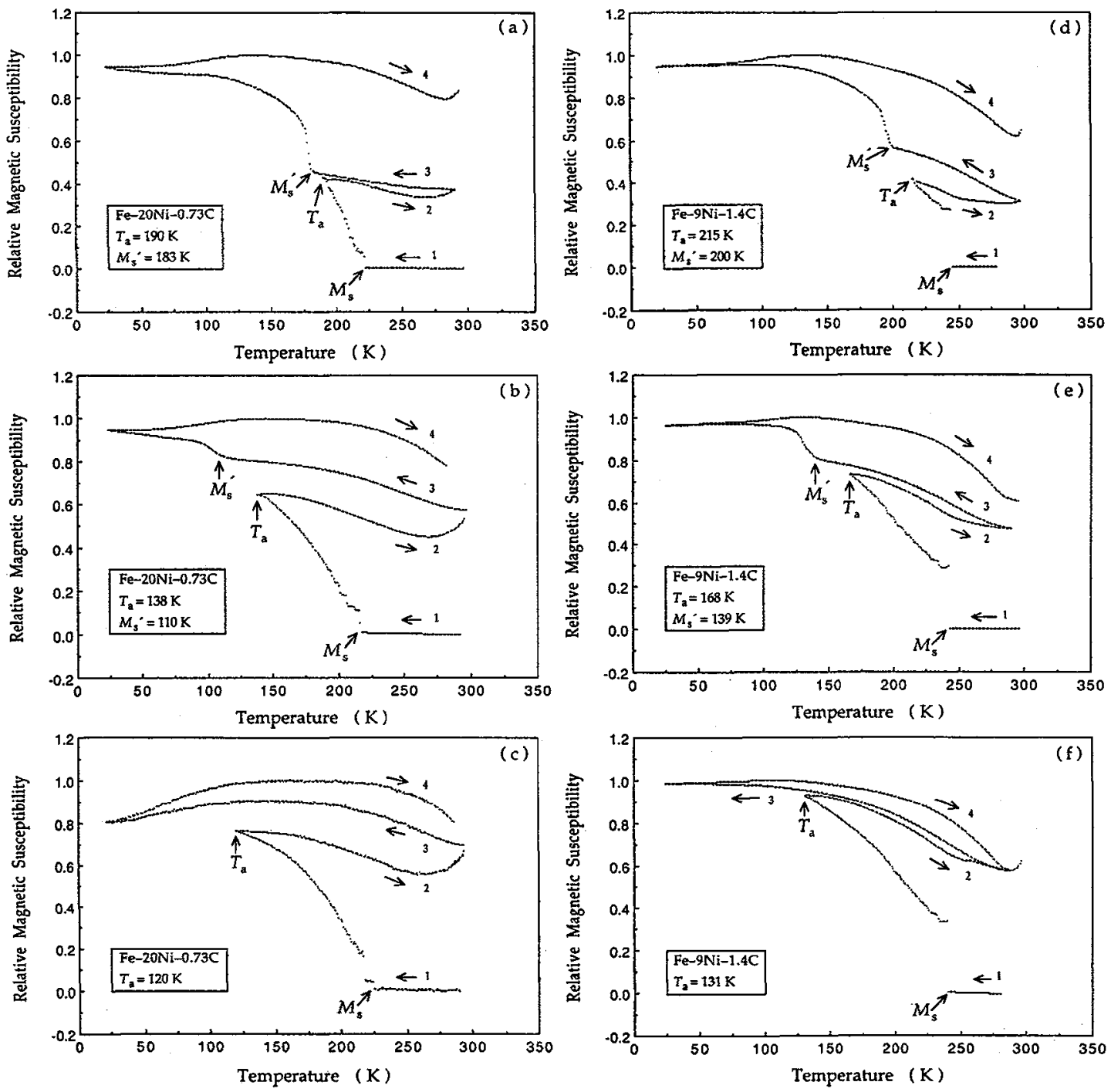

Figure 1: Relative magnetic susceptibility of alloys having lower Ni-content during two-step cooling experiment. 


\section{RESULTS AND DISCUSSIONS}

Several magnetic susceptibility results of the alloys measured during the two-step cooling procedures with changing $T_{\mathrm{a}}$ temperatures are shown in Figs 1 and 2 . It can be seen that, for both groups of alloys with different magnetic properties, martensitic transformation started at $M_{\mathrm{s}}$ temperature during the first step of cooling, and the $M_{\mathrm{s}}$ temperature was lowered to a much lower temperature of $M_{\mathrm{s}}^{\prime}$ during the second step of cooling. It can also be noted that with decreasing $T_{\mathrm{a}}$ (increasing the amount of martensite), both the $M_{\mathrm{s}}{ }^{\prime}$ temperature and the intensity of the transformation occurring at $M_{\mathrm{s}}{ }^{\prime}$ temperature decrease for all the alloys. These observations suggest that the magnetic properties of the alloys have no drastic effects on the stabilization of retained austenite. If $T_{\mathrm{a}}$ is low enough, the martensitic transformation can be completely inhibited during the second step of cooling as shown in Figs 1c and 1f. The fact that the stabilization phenomenon takes place even in an alloy containing a very small amount of carbon, e.g., Fe-33.5Ni$0.009 \mathrm{C}$ alloy as shown in Fig. 2 , indicates that, in addition to the carbon diffusion, the previously formed martensite may also contribute to the stabilization of retained austenite.
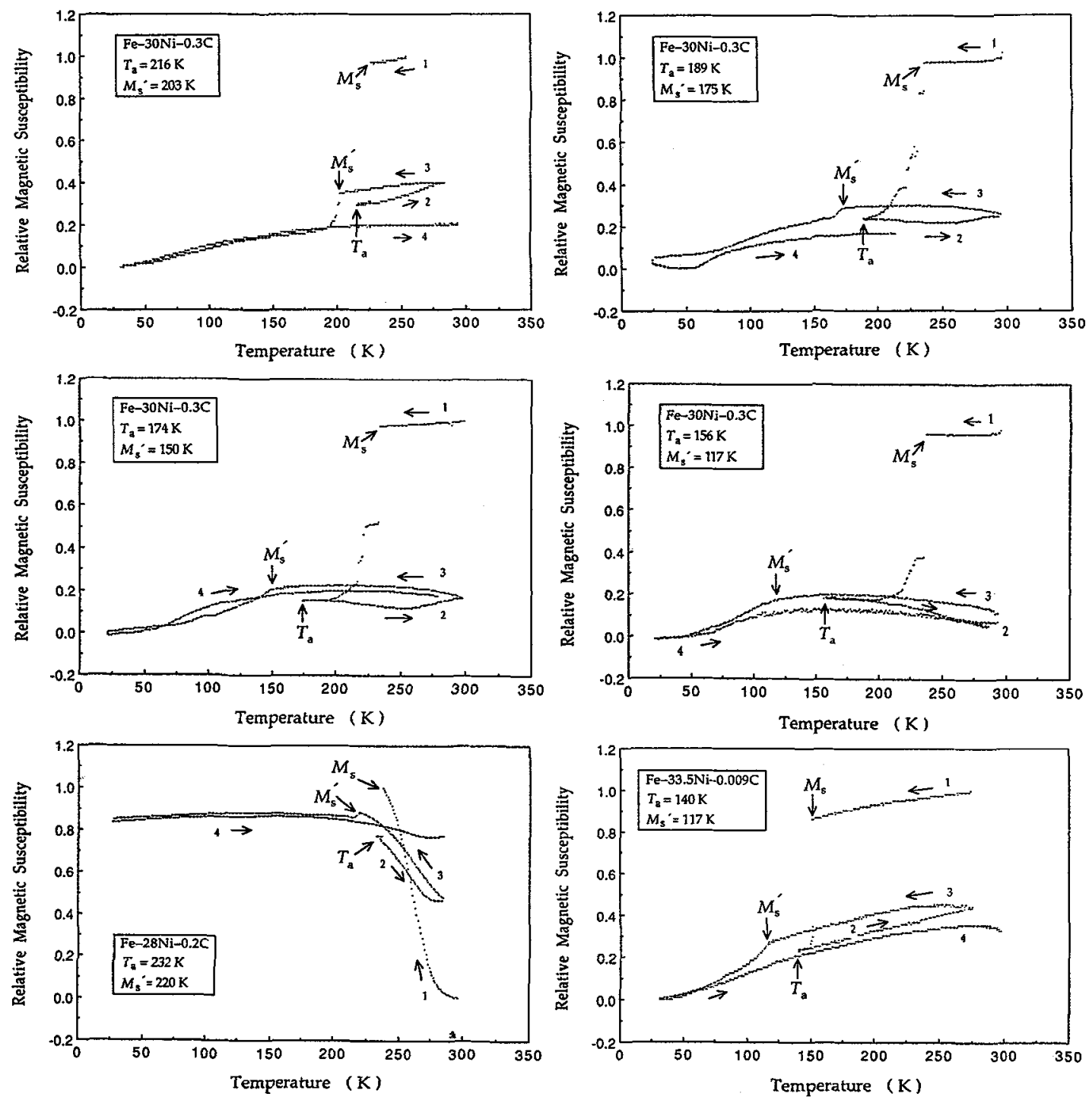

Figure 2: Relative magnetic susceptibility of alloys having higher Ni-content during two-step cooling experiment. 
Values of $M_{\mathrm{s}}, T_{\mathrm{a}}, M_{\mathrm{s}}$ and the corresponding volume fraction of martensite, $f\left(T_{\mathrm{a}}\right)$, are given in detail in [10]. By plotting $\Delta M_{\mathrm{s}}$ as a function of $f\left(T_{\mathrm{a}}\right)$ in Fig. 3 for two alloys with low Ni-content, it can be seen that $\Delta M_{\mathrm{s}}$ increases with increasing $f\left(T_{\mathrm{a}}\right)$. By plotting $\Delta M_{\mathrm{s}}$ as a function of $M_{\mathrm{s}}-T_{\mathrm{a}}$, which can be assumed to be proportional to the volume fraction of martensite, for Fe-30Ni-0.3C alloy in Fig. 4, it can be seen that $\Delta M_{\mathrm{s}}$ increases with increasing $M_{\mathrm{s}}-T_{\mathrm{a}}$, i.e., it increases with increasing $f\left(T_{\mathrm{a}}\right)$. These results indicate that, for both paramagnetic and ferromagnetic austenite phases, the stabilization phenomenon is strongly related to the amount of martensite formed previously in specimens. Under the same aging conditions, the larger the amount of martensite formed during the first cooling, the more difficult will be the transformation of retained austenite into martensite during the second step of cooling.

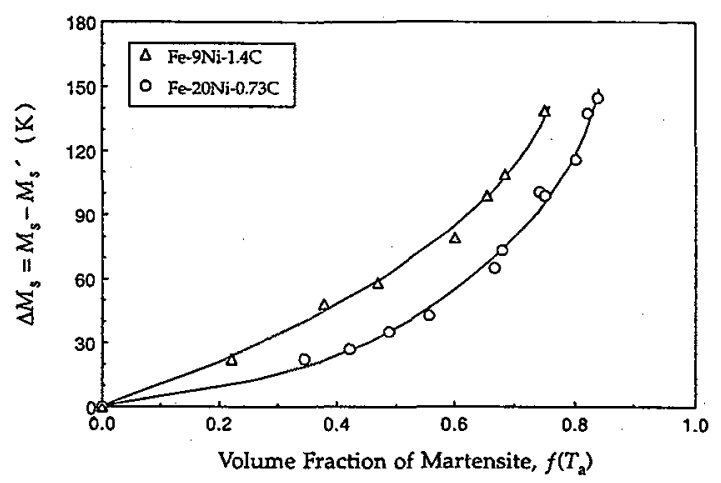

Figure 3: $\Delta M_{\mathrm{s}}$ as a function of the volume fraction of martensite formed during the first step of cooling for the alloys indicated.

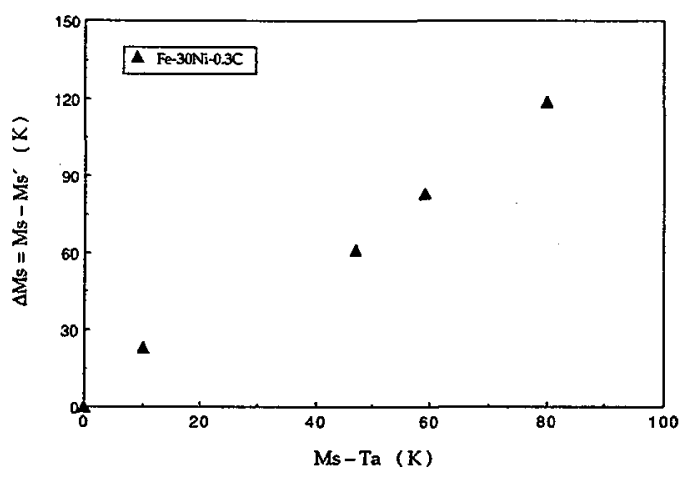

Figure 4: $\Delta M_{\mathrm{s}}$ as a function of undercooling below $M_{\mathrm{s}}$ during the first step of cooling, $M_{\mathrm{s}}-T_{\mathrm{a}}$, for an Fe-30Ni$0.3 \mathrm{C}$ alloy.

It is known that, when a crystallite of martensite phase is produced, accommodation of the volume expansion and transformation shear strains leads to a spontaneous deformation of the austenite surrounding the growing martensite embryo, which will produce dislocation arrays in the austenite/martensite boundaries [11] and an internal stress field in the retained austenite phase [12,13,14]. When the athermal martensitic transformation is stopped at an arrest temperature $T_{\mathrm{a}}$, and aging occurs, segregation of carbon atoms to martensite/austenite phase boundaries and relaxation of stresses at these boundaries will not only reduce the amount of available nucleation sites but also anchor the martensite/austenite phase boundaries.

$X$-ray diffraction results $[13,14]$, have also shown that the austenite lattice parameter decreases linearly with decreasing temperature before the martensitic transformation starts, while a significant drop at the start of martensitic transformation occurs and it decreases continuously with lowering the temperature (increasing the amount of martensite). The austenite lattice parameter and the austenite peak width was not recovered to the original values when the sample was heated back to room temperature. In addition, the diffraction peaks of the austenite phase broadened. The decrease in austenite lattice parameter during cooling at temperatures above $M_{\mathrm{s}}$ temperature is due to the thermal contraction of the lattice." The broadening of the austenite diffraction peaks due to martensitic transformation was explained by a nonuniform internal stress field in retained austenite due to the existence of the martensite phase, while the reduction of the austenite lattice parameter was attributed to the result of a compressive stress field acting on the retained austenite by its surrounding martensites. The results indicate that the internal stress field in retained austenite induced by the martensitic transformation can not relax completely at room temperature. Although it is generally accepted that the retained austenite is stressed during the martensitic transformation, a complete pattern of the internal stress field is still not yet obtained.

Since the internal stress in retained austenite increases with increasing the amount of martensite and the internal stress field exists in retained austenite (can not relax completely) even after the sample was aged at RT $[13,14]$, it is then a logical approach to assume that the further martensitic transformation process during the second cooling was inhibited by the internal stress. Thus, further cooling below $T_{\mathrm{a}}$ temperature is needed in order to obtain enough driving force for the transformation to take place. 
Thus, we propose that the direct reason for the stabilization of retained austenite during two-step cooling experiments is due to the internal resisting stress induced by the previously formed martensite. Segregation of carbon atoms to martensite/austenite phase boundaries and stress relaxation at these boundaries can reduce the amount of available potential nucleation sites and anchor the previously formed martensite/austenite phase boundaries, and thus they are the necessary conditions for the stabilization phenomenon to occur.

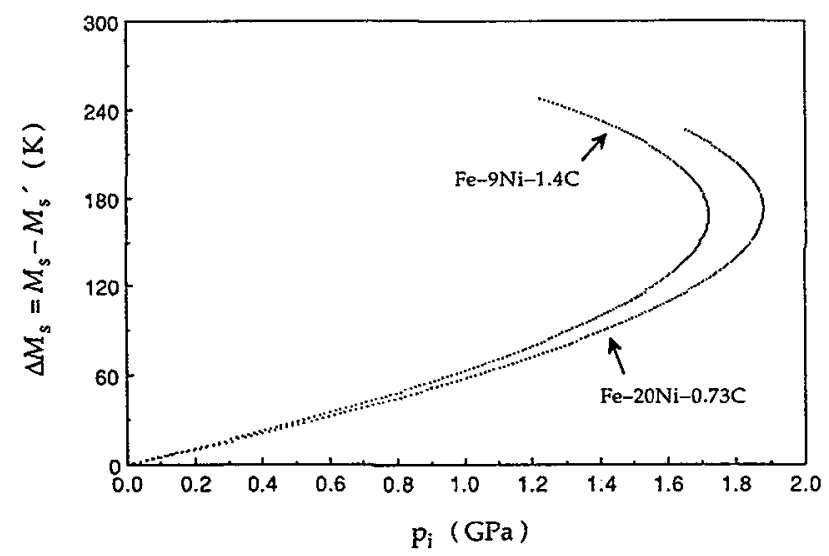

Figure 5: Calculated relationship between the hydrostatic pressure, $\mathrm{p}_{\mathrm{i}}$, and $\Delta M_{\mathrm{s}}$ for the alloys indicated.

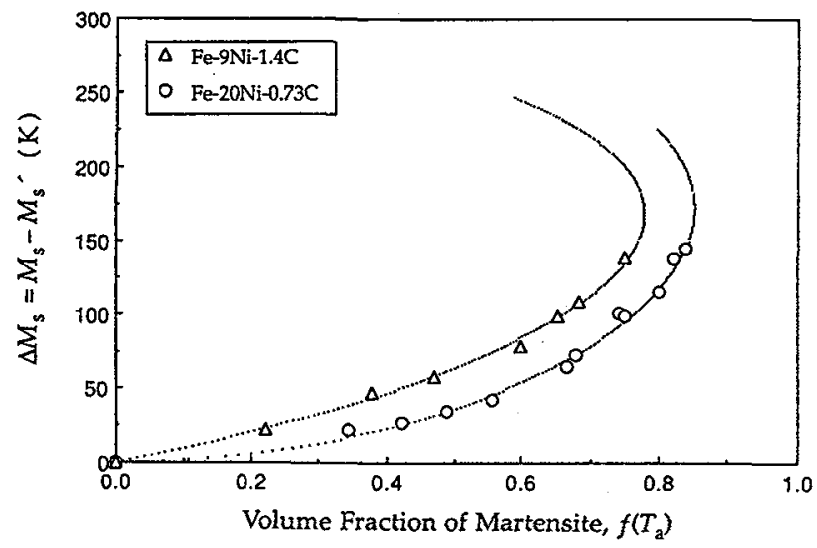

Figure 6: Calculated relationship (dashed lines) between volume fraction of previously formed martensite, $f\left(T_{\mathrm{a}}\right)$, and $\Delta M_{\mathrm{s}}$ for the alloys indicated. $\Delta$ and $o$ are experimental results.

By assuming that the total internal stress resisting the subsequent martensitic transformation in retained austenite phase can be simplified as a hydrostatic compressive stress, $\mathrm{p}_{i}$, the results can be analysed thermodynamically. According to Patel and Cohen [15], the change in $M_{\mathrm{s}}$ temperature due to the presence of the hydrostatic pressure (simplified internal resisting stress), $p_{i}$, can be calculated from the following equation:

$$
\left.\Delta \mathrm{G}_{\mathrm{c}}^{\gamma \rightarrow \alpha^{\prime}}\right|_{\mathrm{T}=M_{s}^{\prime}}-\left.\Delta \mathrm{G}_{\mathrm{c}}^{\gamma \rightarrow \alpha^{\prime}}\right|_{\mathrm{T}=M_{\mathrm{s}}}+\mathrm{p}_{\mathrm{i}} \varepsilon_{0} \mathrm{~V}_{\mathrm{m}}=0
$$

Here the Gibbs chemical free energy change accompanying the transformation is calculated according to Kaufman and Hillert [16]. By using approximate values of $\varepsilon_{0}=0.0298$ and $V_{m}=7.11 \mathrm{~cm}^{3} / \mathrm{mol}$ [17], the relationship between $\mathrm{p}_{\mathrm{i}}$ and $\Delta M_{\mathrm{s}}$ can be calculated by using Eq. (1) as shown in Fig. $5[8,10]$.

It needs to be kept in mind that the relationship between the internal resisting stress in retained austenite and the amount of previously formed martensite is not exactly known at present. However, if the 
relationship between the internal resisting stress, $p_{i}$, and the amount of previously formed martensite, $f$, obeys a quadratic relationship $[8,10]$ :

$$
\mathrm{p}_{\mathrm{i}}=\mathrm{a} f+\mathrm{b} f^{2}
$$

the calculated relationship between $\Delta M_{\mathrm{s}}$ and $f\left(T_{\mathrm{a}}\right)$ fits well with the experimental data as shown in Fig. 6.

\section{CONCLUSIONS}

Based on the results obtained in the present work the following conclusions can be drawn:

1) The magnetic properties of alloys do not have drastic effects on the nature of the stabilization of retained austenite. The stabilization phenomenon can also be observed in an alloy having very low carbon content, i.e., Fe-33.5Ni-0.009C.

2) Under the same aging conditions, the change in $M_{\mathrm{s}}$ temperature, $\Delta M_{\mathrm{s}}$, increases with increasing the amount of previously formed martensite, $f\left(T_{\mathrm{a}}\right)$. The transformation of retained austenite to martensite can be completely inhibited if the arrest temperature, $T_{\mathrm{a}}$, is low enough.

3) It is proposed that the direct reason for the stabilization of retained austenite during two-step cooling experiment is due to the internal resisting stress induced by previously formed martensite. The segregation of carbon atoms to lattice defects and martensite/austenite phase boundaries and the stress relaxation at these boundaries are the necessary conditions for the stabilization phenomenon to occur.

4) If the internal resisting stress in retained austenite can be simplified to be a hydrostatic compressive stress, $\mathrm{p}_{\mathrm{i}}$, and if $\mathrm{p}_{\mathrm{i}}$ and $f\left(T_{\mathrm{a}}\right)$ obey a quadratic relationship: $\mathrm{p}_{\mathrm{i}}=\mathrm{a} f+\mathrm{b} f^{2}$, the calculated relationship between $\Delta M_{\mathrm{S}}$ and $f\left(T_{\mathrm{a}}\right)$ fits well with the experimental results.

\section{Acknowledgements}

The authors want to thank Prof. J. Pietikäinen for helpful discussions. The research was originally supported by the Finnish Centre for International Mobility and the Academy of Finland.

\section{References}

[1] S. G. Glover, J. Iron Steel Inst. 200 (1962) 102.

[2] B. Edmondson, Acta Metall. 5, 208 (1957).

[3] K. R. Kinsman and J. C. Shyne, Acta Metall. 14 (1966) 1063.

[4] K. R. Kinsman and J. C. Shyne, Acta Metall. 15 (1967) 1527.

[5] T. K. Sanyal and R. Brook, Metal Sci. 9 (1975) 135.

[6] G. White and R. Brook, Metal Sci. 11 (1977) 152.

[7] S. G. Glover and T. B. Smith, Symposium on the Mechanism of Phase Transformations in Metals, Monograph No.18 (1955) pp. 265-276, Institute of Metals, London.

[8] Z. L. Xie, Y. Liu and H. Hänninen, Acta Metall. Mater. 42 (1994) 4117.

[9] G. F. Bolling and R. H. Richman, Acta Metall. 18 (1970) 673.

[10] Z. L. Xie, Doctor thesis, Helsinki Univ. of Technology. Acta Polytechnica Scandinavica, Ch 219 (1994).

[11] E. S. Machlin and M. Cohen, Trans. Am. Inst. Min. Engrs. 191 (1951) 746.

[12] B. Edmondson and T. Ko, Acta Metall. 2 (1954) 235.

[13] K. Ya. Golovchiner, Phys. Met. Metallogr. 37 (1974) 126.

[14] Y Tanaka and K. Shimizu, Trans. Japan Inst. Metals 21 (1980) 42.

[15] J. R. Patel and M. Cohen, Acta Metall. 1, 531 (1953).

[16] L. Kaufman and M. Hillert, Martensite (edited by G. B. Olson and W. S. Owen), pp. 41-58, ASM International (1992).

[17] Z. L. Xie, B. Sundqvist, H. Hänninen and J. Pietikäinen, Acta Metall. Mater. 41 (1993) 2283. 